\title{
The relationship between acute stress, food intake, endocrine status and life history stage in juvenile farmed Atlantic salmon, Salmo salar.
}

\author{
N.W.Pankhurst ${ }^{\mathrm{a}}{ }^{*}$, S.L. Ludke ${ }^{\mathrm{a}}$, H.R. King ${ }^{\mathrm{b}}$, R.E. Peter ${ }^{\mathrm{c}}$ \\ ${ }^{a}$ Fish Endocrinology Laboratory, Faculty of Science Engineering and IT, James Cook \\ University, Townsville, Queensland 4811, Australia. \\ ${ }^{b}$ Salmon Enterprises of Tasmania, P.O. Box 1 Wayatinah, Tasmania 7140, Australia \\ ${ }^{c}$ School of Biological Sciences, University of Alberta, Edmonton, Alberta TLG 6E9, Canada \\ * Corresponding author and address for correspondence. Science, Environment, Engineering \\ and Technology Executive, Gold Coast Campus, Griffith University, PMB 50 Gold Coast \\ Mail Centre, Queensland 9726, Australia. Tel.: +61 75552 8033; Fax: +61 75552 8220; E- \\ mail: n.pankhurst@griffith.edu.au
}

\begin{abstract}
Different life history stages of juvenile Atlantic salmon around the period of smoltification were subjected to short term stress (confinement) over two sampling years using separate cohorts of hatchery-reared fish. In the first year, confinement stress suppressed subsequent feeding in smolts and post-smolts, but not parr, in association with elevated plasma cortisol levels. Post-smolts showed much lower levels of food intake than either parr or smolts. Plasma ghrelin levels were unaffected by stress in any group. In the second study year, presmolts had very low food intake and this was further suppressed following stress. Higher
\end{abstract}


food intake levels in smolts were strongly inhibited post-stress. Both pre-smolts, and smolts showed elevated levels of plasma cortisol and glucose, and suppressed plasma ghrelin levels. Across both study years, stress that was accompanied by elevated plasma cortisol levels resulted in suppression of feeding, whereas a predicted association of suppressed plasma ghrelin levels with reduced food intake, was present only in the second year. The results of the present study indicate that elevated plasma cortisol is a consistent endocrine correlate of stress-suppression of feeding. It is also apparent that the peri-smolt period is associated with markedly reduced feeding in this stock of Atlantic salmon.

Key words: Atlantic salmon; Stress; Feeding; Cortisol; Ghrelin

\section{Introduction}

Salmonid fishes show a natural period of heightened hypothalamic-pituitary interrenal (HPI) activity, and subsequent cortisol production, along with reduced appetite and other behavioural changes, around the period of smoltification - the physiological pre-adaptation for transition from the fresh-water to the marine habitat (Barton et al., 1985; Carey and McCormick, 1998; Ewing and Rodgers, 1998; Beckman et al., 2000; Nielsen et al., 2001; Handeland et al., 2003). Similar effects on endocrine and electrolyte status, and feeding occur when fish are abruptly transferred from fresh- to salt-water (MacLeod, 1977; Usher et al., 1991; Arnesen et al., 1993; Damsgård and Arnesen, 1998). Most fish recover metabolic and endocrine balance over a period of days or weeks post-transition or transfer, with attendant resumption of feeding; however, the rate at which individual fish resume feeding is variable and can take in excess of 30 days (Usher et al., 1991; Arnesen et al., 1993, 2003). In culture situations, variable return to feeding after transfer from fresh-water hatcheries to 
marine grow-out situations may have significant effects on the subsequent growth trajectory of fish in sea-water. Significant proportions of transferred cohorts may fail to grow at all (the fish are referred to as 'stunts' or 'failed smolt') and subsequently die. The conditions that generate stunting are not well understood; however, in Atlantic salmon, the condition has been associated with elevated growth hormone (GH) levels (Bjornsson et al., 1988), and insulin-like growth factor I (IGF1) levels were found to be lower than normal in Atlantic salmon identified as 'stunts' 6 weeks after transfer (Dyer et al., 2004). It is unclear whether these changes result in, or from stunting, and it is also not known whether stress effects associated with husbandry might augment or stimulate failure to thrive, post-transfer to seawater.

Physiological stress generated by normal husbandry practices in aquaculture can have an inhibiting affect on growth of cultured stocks both through the suppression of appetite and feeding behaviour (Schreck et al., 1997; McCormick et al,. 1998), and through inhibitory effects of stress on the secretion and action of GH and IGF1 (Pickering, 1993; Pankhurst and Van Der Kraak, 1997; Dyer et al., 2004). One of the primary endocrine responses to stress in fish is a consistent elevation in plasma cortisol (Sumpter, 1997), and this can have a direct effect on growth due to its catabolic effects on metabolism (Pickering, 1993; Pankhurst and Van Der Kraak, 1997). However, it is also clear that exogenous cortisol can also inhibit food intake in fish (Gregory and Wood, 1999; Peterson and Small, 2005), although the mechanism involved has yet to be determined.

Appetite control in fish as in other vertebrates is complex, with interaction between a number of orexigenic (stimulatory) and anorexigenic (inhibitory) neuroendocrine and endocrine factors. Appetite stimulants include neuropeptide Y (NPY) and the gastric peptide ghrelin (which appears to exert at least some of the actions through NPY), whereas appetite is inhibited by corticotropin releasing factor (CRF), CRF-related peptides, gastrin, 
cholecystokinin and bombesin, and glucagon-like peptide (reviewed in Lin et al., 2000; Bernier and Peter, 2001a; Volkoff et al., 2005).

The role of stress in modifying these appetite signals has not been extensively investigated in fish, although recent work in rainbow trout shows that short term stress can suppress plasma ghrelin levels (Pankhurst et al., 2007). Plasma ghrelin levels do show elevation in fasted fish (Unniappan et al., 2004; Pankhurst et al., 2007), and exogenous ghrelin administered both via intraperitoneal and intracerebroventricular routes stimulates feeding (Unniappan et al., 2004; Shepherd et al., 2007), indicating that as in other vertebrates (Unniappan and Peter, 2005), ghrelin can be orexigenic in fish. However, a recent study on rainbow trout failed to demonstrate any effect of exogenous ghrelin on food intake, or any post-prandial change in plasma ghrelin levels (Jönsson et al., 2007). In mammals, increases in plasma corticosteroid levels suppress plasma ghrelin levels, and this effect can be reversed by adrenalectomy (Otto et al., 2004; Proulx et al., 2005). This suggests that one mechanism of stress suppression of feeding in fish may be through elevation of cortisol, and subsequent suppression of plasma ghrelin levels. CRF expression also increases in the hypothalamic and forebrain areas of fish following acute stress (reviewed in Bernier, 2006) which may also contribute to appetite suppression.

The present study investigated the response of juvenile cultured Atlantic salmon from a Tasmanian stock, around the period of smoltification to modest stress regimes that reflect normal handling and husbandry practice, in terms of effects on appetite suppression and endocrine status. Stocks of parr, pre-smolt, smolt and post-smolt were confined for short periods and then subsequent feeding behaviour and plasma levels of cortisol and glucose (measures of HPI-axis and catecholamine stimulation, respectively; Sumpter, 1997), and ghrelin (as a potential orexigenic factor; Unniappan and Peter, 1995) were measured. This 
assessment forms the basis of longer term experiments examining the effects of repeated stress on growth in this stock of Atlantic salmon.

\section{Materials \& Methods}

\subsection{Fish stocks and husbandry}

In 2004, fish were sourced from the 2003 Salmon Enterprises of Tasmania (Saltas) production cohort and selected as:

Parr - graded small fish (mean weight 50.2g) that had been held on natural photoperiod since October 2003 and which had failed to undergo austral spring smoltification; Smolts - graded medium fish (mean weight 129.4g) held on natural photoperiod since 2003 and which had undergone normal spring smoltification;

Post-smolts - graded large fish (mean weight 211.2g) that had been held on natural photoperiod from October 2003 to June 2004, then exposed to 7 weeks of 22L:2D long-day photoperiod to induce early smoltification. Following smoltification, fish were returned to natural photoperiod from mid-August until the commencement of experiments in November 2004.

In 2005, two stocks of fish from the 2004 Saltas commercial production cohort were used: Pre-smolts (mean weight 78.0g) were exposed to natural photoperiod from October 2004 until the time of experiment (late August, 2005). These fish were $\sim 1$ month from the expected commencement of normal austral spring smoltification in un-manipulated fish. Smolts (mean weight 77.1g) had been held on natural photoperiod from October 2004 until mid-May 2005 when they were transferred to 22L:2D for 7 weeks to induce early 
smoltification as described previously. These fish were then transferred back to natural photoperiod until the experiment began.

Fish in both years were held in $4 \mathrm{~m}^{3}$ outdoor tanks supplied with river water at natural temperature and fed to satiation on a commercial diet (Skretting, Australia). The smoltification status of each fish stage (i.e. parr, pre-smolt, smolt, post-smolt) was assessed on the basis of standard commercial protocols for the evaluation of smoltification in the source populations (\% survival and blood osmolality of a sub-sample of fish exposed to seawater at $34 \%$ o for $48 \mathrm{~h})$.

\subsection{Experimental protocols}

Experiment 1: Effect of confinement stress on feeding and endocrine status

In November 2004, 100 parr, smolts or post-smolts as defined above were transferred from outdoor $4 \mathrm{~m}^{3}$ holding tanks at the Saltas Wayatinah hatchery facility (Central Highlands, Tasmania) into indoor $4 \mathrm{~m}^{3}$ tanks (one tank per group) supplied with recirculating water held at $10^{\circ} \mathrm{C}$, under simulated natural photoperiod, and left for 2 days to settle. During this period, fish were not fed. Prior to transfer, 7 fish from each outdoor stock were netted from the outdoor tanks, anaesthetised and blood sampled as described below to provide baselines for plasma levels of cortisol and glucose from undisturbed fish. For this and all subsequent sampling, a sample size of 7 was chosen to balance the need for $n$ values large enough for robust small-sample statistics, but small enough that all fish could be sampled within the latency period for likely changes in plasma constituents occurring as a result of the sampling procedure itself. On the evening of the second day, 7 fish (No- confinement-stress sample) from each indoor group were transferred to a 450-l test tank containing static aerated water, and left undisturbed overnight. The 450-l test tank facilitated assessment of feeding and 
allowed simultaneous capture of all fish with a single net sweep for anaesthesia and sampling. At approximately 0900h, fish were offered a 2-minute feed (150 pellets per bin) of 2, 3 or $4 \mathrm{~mm}$ pellets for parr, smolts and post-smolts respectively. At the end of the feeding period, all fish were netted, anaesthetised and sampled as described below. Uneaten pellets in the test tank were collected and counted. Twenty-eight additional fish from each group were then transferred from each of the respective $4 \mathrm{~m}^{3}$ holding tanks to an aerated 50-l confinement bin for 1h, then distributed to separate 450-l test tanks at 7 fish per tank. Each separate group of fish was then offered a feed as before, and the fish netted and sampled at $0,1,3$ or $6 \mathrm{~h}$ after the confinement stress episode, for comparison with the no-confinement-stress group.

Experiment 2: Effect of confinement stress on individual endocrine and feeding response

Groups of pre-smolts and smolts in 2005 were transferred from outdoor tanks to indoor $4 \mathrm{~m}^{3}$ tanks and held unfed at $10^{\circ} \mathrm{C}$ for 2 days as before. On the evening of day 2, fish were distributed at 12 or 13 fish per tank to four 450-l test tanks for each group. The following morning ( 0900h), fish were presented with a 3-minute feed of 3mm pellets at $~ 1 \%$ of body weight, then netted and anaesthetised for sampling as unstressed pre-smolt or smolt groups. Additional groups of pre-smolts and smolts were transferred to indoor $4 \mathrm{~m}^{3}$ indoor tanks as before but then exposed to $1 \mathrm{~h}$ of confinement stress in 40-l confinement bins (12-13 fish per confinement bin) before transfer to the 450-l test tanks at 12-13 fish per tank as before. Fish were then immediately presented with the 3-minute test feed, then anaesthetised and sampled as stressed pre-smolt or smolt groups. Individual food intake was measured post-mortem as described below.

\subsection{Blood sampling}


Netted fish were rapidly anaesthetised in 25ppm Aqui-S (Crop \& Food, New Zealand), killed with a cranial blow then blood sampled by caudal puncture using $1 \mathrm{ml}$ pre-heparinised syringes and 22G needles. Plasma was separated by centrifugation and aliquotted at $10 \mu \mathrm{l}$

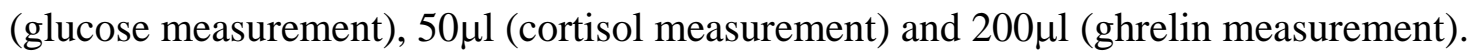
Samples for ghrelin measurement were acidified by addition of $10 \mu \mathrm{l}$ of $1 \mathrm{~N} \mathrm{HCl}$ and stabilised with $3 \mu \mathrm{l}$ 10mg.ml $\mathrm{m}^{-1}$ phenyl-methyl-sulfonyl-fluoride (Sigma Aldrich) in methanol. Plasma samples were then frozen for storage and transport to James Cook University for assay. Oesophageal cavities of all fish from the 2005 experiment were then opened with a scalpel and the total number of food pellets ingested by each fish was counted.

\subsection{Hormone assay}

Plasma ghrelin levels were measured with a heterologous assay using a ${ }^{125} \mathrm{I}$ radioimmunoassay kit for human ghrelin (Linco Research Inc, St Charles, Missouri) which is specific for biologically active (octanoylated) ghrelin. Plasma samples were stabilised as described above, and heparin levels in plasma samples were kept as recommended at less than $5 \mathrm{U} \mathrm{ml}^{-1}$ to avoid false assay positives. The assay was validated using serial dilution of plasma which in all cases gave parallel displacement to that of assay standards. Inter-assay variation was assessed using repeat measurements of quality control standards provided in the kit and was (\%CV[n]) 8.1[7].

Plasma cortisol levels were measured by RIA using the protocol described in Pankhurst and Sharples (1992) and an antibody purchased from Bioclone Australia Pty. Ltd. Plasma was extracted with ethyl acetate prior to assay, solvent extracts dried down in assay tubes then reconstituted with assay buffer. Extraction efficiency was estimated from recovery of ${ }^{3} \mathrm{H}$-cortisol from aliquots of pooled plasma samples and assay values were corrected 
accordingly. Inter-assay variability measured using aliquots of a pooled internal standard was (\%CV[n]) 6.5[7].

Plasma levels of glucose were determined spectrophotometrically using a diagnostic kit (ThermoElectron, Melbourne, Australia) validated against a standard curve.

\subsection{Statistics}

Comparisons between means were made using one-way ANOVA and subsequent Tukeys b tests. Where necessary, data were square root, or log transformed to satisfy the requirements for homogeneity of variances. Feeding data were assessed using Chi-squared tests. All analyses were conducted using the SPSS (version 13.0) statistical package.

\section{Results}

\subsection{Effect of confinement stress on feeding and endocrine status}

Parr exposed to confinement stress in 2004 showed no discernable reduction in group feeding as a result of stress, however, there was a significant change in the proportion of eaten vs uneaten pellets across time, with pellet ingestion increasing at 1,3 and $6 \mathrm{~h}$ post-stress (Table 1). In contrast, both smolts and post-smolts showed depressed feeding levels immediately after stress but recovery by $1 \mathrm{~h}$ post-stress. Feeding among post-smolts was substantially lower at all times than in either of the other two groups. Because feeding was assessed at group level in 2004, it is not known whether this resulted from generally lower food intake by all post-smolts, or food intake by fewer fish. However, it is clear that there was effectively no feeding by any post-smolts immediately after stress. 
Plasma cortisol levels in parr were elevated 0 and $1 \mathrm{~h}$ after confinement in relation to undisturbed fish and fish at 6h post-confinement, but not different from those in noconfinement-stress fish (Fig.1). Plasma glucose levels were unchanging over time at $\sim 4 \mathrm{mM}$ throughout (Fig. 1). Smolts showed a marked increase in plasma cortisol at 0 and 1 h poststress (62 and 53 ng. $\mathrm{ml}^{-1}$ respectively) and had returned to intermediate levels at 3, and $6 \mathrm{~h}$ post-stress. Plasma glucose levels were elevated in undisturbed smolts relative to preconfinement samples but were not different from levels in fish at other times (Fig. 1). Plasma cortisol levels in post-smolts were high $\left(\sim 155 \mathrm{ng} \cdot \mathrm{ml}^{-1}\right)$ at 0 and 1 h post-confinement but fell to lower levels ( 30ng. $\left.\mathrm{ml}^{-1}\right)$ at 3 and $6 \mathrm{~h}$ post-stress. Initial glucose levels in post-smolts were high ( 9mM) but lower (5-7nM) and not different at other times (Fig.1). Plasma ghrelin levels were variable within groups and did not change significantly across time in any group of fish (Fig. 2). Among fish not exposed to confinement stress, ghrelin levels were lower in post-smolts than in smolts but not different from those in parr.

\subsection{Effect of confinement stress on individual endocrine and feeding response}

Food ingestion by pre-smolts sampled in 2005 was low in terms of mean number of pellets eaten, total number of pellets eaten and the proportion of fish feeding; however, only the total number of pellets consumed was reduced following stress (Table 2). In contrast, smolts had high pellet consumption but this was suppressed by stress across all three measures (Table 2). Plasma cortisol levels were low in both groups of unstressed fish $\left(<15 \mathrm{ng} \cdot \mathrm{ml}^{-1}\right)$, and elevated by confinement with higher values in stressed smolts than in stressed pre-smolts (30 and 23 ng. $\mathrm{ml}^{-1}$ respectively) (Fig. 3). Plasma glucose levels were similarly elevated by stress, however, in this case, highest values occurred in pre-smolts (6.6 and 5.9mM for pre-smolts, and smolts respectively) (Fig. 3). Plasma ghrelin levels were similar in both groups of 
unstressed fish, and also suppressed in both groups post-stress, with greater suppression in pre-smolts than smolts (Fig. 3).

\section{Discussion}

Confinement stress elevated plasma cortisol levels in parr in the present study over values found in undisturbed fish but not those of fish following transfer to indoor tanks prior to confinement experiments. Stress-induced changes were small with peak plasma cortisol levels of $27 \mathrm{ng} \cdot \mathrm{ml}^{-1}$, $1 \mathrm{~h}$ after stress. This suggests that fish may not have completely adjusted to indoor conditions after transfer but also that the overall HPI response to stress was modest. Changes in the present study were lower than responses to stress of sexually immature adults of this stock kept in freshwater, where low-water stress typically generates cortisol levels of 60ng.ml ${ }^{-1}$ (Thomas et al. 1999). Plasma glucose levels in parr in the present study were unchanging at about $\sim 4 \mathrm{mM}$, similar to basal levels in unstressed rainbow trout (Flos et al., 1988; Pankhurst et al., 2007), and coho salmon (Iwama et al., 1995). In contrast, smolts showed a marked increase in plasma cortisol levels (peak of 59ng.ml ${ }^{-1}$ immediately after confinement) and did appear to have adjusted to transfer from outdoor to indoor tanks in terms of post-transfer cortisol levels. Plasma glucose was strongly elevated in fish sampled from outdoor tanks but was lower in fish allowed to acclimate to indoor tanks (noconfinement-stress sample) and didn't change further after confinement stress. The elevated glucose levels in fish sampled from the outdoor tanks may reflect a catcholamine-mediated increase as a result of capture and sampling that took a few minutes longer than from indoor tanks. Alternatively, elevated glucose levels may be the normal condition in un-manipulated smolts and post-smolts, but the fall in both these groups after acclimation to indoor tanks (where sampling could be conducted more rapidly) suggests that elevations from fish from 
outdoor tanks do reflect the increased time taken to sample. Post-smolts had higher basal cortisol levels (40-80ng. $\mathrm{ml}^{-1}$ ) and showed a very marked elevation following stress (peak levels of 158ng.ml ${ }^{-1}$ immediately after confinement), with a glucose profile that was similar to that of smolts. Other workers have also reported heightened responses to stress in salmonids around the time of smoltification. Plasma cortisol levels in Atlantic salmon parr rose from 3 to 11 ng.ml ${ }^{-1}$ following confinement stress, whereas those of smolts changed from 10-242 ng.ml ${ }^{-1}$ (Carey and McCormack, 1998). Both groups also showed increased plasma glucose levels but values were higher $(\sim 7.5 \mathrm{mM})$ in smolts than in parr $(\sim 6 \mathrm{mM})$. Barton et al. (1985) reported that coho salmon Oncorhynchus kisutch had increasing basal levels of cortisol as smoltification approached, and that the peak levels following stress rose from $\sim 80 \mathrm{ng} . \mathrm{ml}^{-1}$ in parr to $\sim 170 \mathrm{ng} . \mathrm{ml}^{-1}$ in smolts. The results of the present and earlier studies are consistent with the view that not only do smolting salmonids have higher basal levels of cortisol, but that there is also heightened sensitivity of the HPI axis to stressors. In 2005 fish sampled in the present study, plasma cortisol levels were again elevated by stress, although here the elevations were lower than in the previous year. In contrast to the previous year, there was a consistent effect of stress on plasma glucose levels, similar to effects in other salmonid species where stress typically elevates plasma glucose levels to 6-8mM (Flos et al., 1988; Iwama et al., 1996; Pankhurst et al., 2007).

Stressed fish in both years of the present study generally displayed short-term suppression of feeding activity, but overlaid on this was an effect of developmental stage. In 2004, parr showed no marked impact of stress on feeding in relation to confinement but some suggestion that feeding was suppressed following transfer to indoor tanks. Both smolts and post-smolts showed suppressed feeding immediately after stress but quite rapid recovery following stress. However, overall food consumption was much lower in post-smolts than either of the other two groups. More articulate assessment of individual feeding in 2005 again showed 
differences between stages. Food consumption in pre-smolts was very low but total pellet ingestion was further suppressed by stress. Unstressed smolts ate 10 times as much as presmolts but showed a marked reduction in individual food consumption, total food consumption and the proportion of fish feeding, following stress. Suppression of feeding in response to various forms of stress has also been reported elsewhere. Daily episodes of acute stress reduced food consumption in Atlantic salmon parr (McCormick et al., 1998), and weekly netting and weighing reduced food consumption of rainbow trout Oncorhynchus mykiss (Hoskonen and Pirhonen, 2006). The effects in trout could be offset to an extent by prior anaesthesia suggesting that the responses were partially mediated by the perception of stress by the fish.

There is less information on the effect of salmonid life-history stage on stress-related effects on feeding. Seawater transfer has been demonstrated to decrease both individual food intake and the proportion of fish feeding in Atlantic salmon smolts (Usher et al., 1991; Damsgård and Arnesen, 1998), Arctic charr Salvelinus alpinus (Arnesen et al., 1993), and yearling steelhead trout O. mykiss (Liebert and Schreck, 2006). However this appears to be as much an effect of salinity change as sensitivity of life history stage, as abrupt exposure of adult rainbow trout to elevated salinity generates similar effects (MacLeod, 1977; McKay and Gjerde, 1985; Craig et al., 2005). The present experiments were all conducted on fish in freshwater and indicate that there is substantially reduced appetite in Atlantic salmon approaching, and after smoltification. Contrary to expectation, smolts in the present study were quite active in terms of basal feeding, compared with post-smolts in 2004, and presmolts in 2005, suggesting that periods either side of smoltification present higher areas of sensitivity in terms of potential disruption to feeding. The implication is that seawater transfer too early, or too long after smoltification may exacerbate the appetite-inhibiting effects of exposure to elevated salinity. 
Stress-related suppression of feeding in the present study was generally associated with increases in plasma cortisol, suggesting that plasma cortisol levels provide a useful correlate for conditions likely to suppress feeding. However, increasing cortisol levels rather than absolute levels appear to be important indicators as in the present study low pre-stress feeding was found in post-smolts in one year with basal cortisol levels of $\sim 40 \mathrm{ng} \cdot \mathrm{ml}^{-1}$, and in the following year in pre-smolts with basal cortisol levels of $\sim 12 \mathrm{ng} . \mathrm{ml}^{-1}$. Examination of the effects of cortisol on feeding in a range of other species suggests that cortisol may be a regulator rather than just a correlate of suppressed appetite and feeding. Implants of cortisol in juvenile rainbow trout that elevated plasma levels to $\sim 200 \mathrm{ng} \cdot \mathrm{ml}^{-1}$ resulted in reduced appetite, growth rates and food conversion efficiency (Gregory and Wood, 1999). Similarly, channel catfish Ictalurus punctatus administered cortisol in feed had plasma cortisol levels of up to 500ng.ml ${ }^{-1}$ in association with reduced feeding and growth (Peterson and Small, 2005). Effects in goldfish Carassius auratus were equivocal with low doses increasing food intake, but high doses having no effect. Food conversion rate was; however, reduced by both doses of cortisol (Bernier et al., 2004). In two other studies where exogenous cortisol was administered but feeding not measured, increases in plasma cortisol were associated with reduced growth in channel catfish (Davis et al., 1985) and rainbow trout (Barton et al., 1987). The mechanisms by which cortisol might suppress growth include the activation of gluconeogenesis using stored lipids and amino acids as preferential energy sources (Davis et al., 1985), and the suppression of plasma levels of IGF1 (Peterson and Small, 2005); however, the mechanism by which cortisol might suppress appetite is less clear. Increasing evidence for the short-term non-genomic effects of steroids including glucocorticoids, in fish and other vertebrates (Thomas , 2003; Pfaff et al., 2004; Tasker et al., 2006) means that acute effects of cortisol on behaviours such as feeding cannot be ruled out. 
An explanation of stress-suppression of appetite may lie in the regulation of the orexigenic gastric peptide ghrelin. As noted earlier, ghrelin has a significant appetite-stimulating effect in mammals (Cummings and Shannon, 2003) and birds (Shousha et al., 2005). The effect is also present in fish (Unniappan and Peter, 2005); however, recent work on rainbow trout failed to show an increase in appetite in response to exogenous ghrelin (Jönsson et al., 2007). In mammals, plasma ghrelin levels are suppressed by exogenous, or endogenous increases in corticosteroids, and normalised by adrenalectomy (Otto et al., 2004; Proulx et al., 2005). There is limited information on the effects of cortisol on plasma ghrelin levels in fish. In a preliminary study in rainbow trout, we detected stress-induced suppression of ghrelin in one experiment, but not two others (Pankhurst et al., 2007), and in the present study, increased cortisol levels were associated with reduced plasma ghrelin in 2005 experiments, but not in 2004. However, post-smolts in 2004 (the group with the highest basal plasma cortisol levels) where feeding activity was low at all times, had lower pre-stress levels of ghrelin than presmolts where feeding activity was high. Collectively, these results suggest that stress and, or elevated plasma cortisol may reduce plasma ghrelin levels but the relationship does not appear to be as consistent as in mammals, and may only be one of a number of factors involved in stress-suppression of appetite in fish.

Stress-generated suppression of appetite may also occur through stimulation of anorexigenic factors such as CRF (reviewed in Bernier, 2006). Intra-cerebro-ventricular injection of CRF inhibits food intake in a dose-dependent manner in goldfish (Bernier and Peter, 2001b), and stress results in elevations in hypothalamic and, or forebrain CRF expression in carp Cyprinus carpio (Huising et al., 2004) and rainbow trout (Bernier and Craig, 2005; Craig et al., 2005; Doyon et al., 2003, 2005, 2006). However, sustained stress, or high levels of cortisol may be associated with reduction in CRF mRNA levels as a result of cortisol-mediated negative feedback (Bernier et al., 1999; Doyon et al., 2006). 
In summary, a consistent effect of confinement stress in the present study was the elevation of plasma cortisol, and this was generally associated with suppression of appetite. There was an effect of developmental stage overlaid on this, with fish before, and after smoltification showing markedly reduced appetite, irrespective of stress status. This indicates that plasma cortisol level is a useful physiological predictor of the likely effect of husbandry or manipulation on feeding, and also that fish either side of smolting are likely to have reduced appetite. Seawater transfer either too soon, or too late in the smoltification period is likely to result in reduced feeding and subsequently growth, post-transfer, as are events in post-transfer husbandry that elevate plasma cortisol.

\section{Acknowledgements}

This study was supported by an Australian Research Council Linkage Grant awarded to NWP, cash and in-kind support from Salmon Enterprises of Tasmania, and research infrastructure support from James Cook University.

\section{References}

Arnesen, A.M., Jorgensen, E.H., Jobling, M., 1993. Feed intake, growth and osmoregulation in Arctic charr, Salvelinus alpinus (L.), following abrupt transfer from seawater to more saline water. Aquaculture 114, 327-338.

Arnesen, A.M., Toften, H., Agustsson, T., Stefansson, S.O., Handeland, S.O., Björnsson, B.Th., 2003. Osmoregulation, feed intake, growth and growth hormone levels in 0+ Atlantic salmon (Salmo salar L.) transferred to sweater at different stages of smolt development. Aquaculture 222, 167-187. 
Barton, B.A., Schreck, C.B., Barton, L.D., 1987. Effects of chronic cortisol administration and daily acute stress on growth, physiological conditions, and stress response in juvenile rainbow trout. Dis. Aquat. Org. 2, 173-185.

Barton, B.A., Schreck, C.B., Ewing, R.D., Hemmingsen, A.R., Patino, R., 1985. Changes in plasma cortisol during stress and smoltification in coho salmon, Oncorhynchus kisutch. Gen. Comp. Endocrinol. 59, 468-471.

Beckman. B.R., Larsen, D.A., Sharpe, C., Lee-Pawlak, B., Schreck, C.B., Dickhoff, W.W., 2000. Physiological status of naturally reared juvenile spring Chinook salmon in the Yakima River: Seasonal dynamics and changes associated with smolting. Trans. Am. Fish. Soc. 129, 727-753.

Bernier, N.J., 2006. The corticotrophin-releasing factor system as a mediator of the appetitesuppressing effects of stress in fish. Gen. Comp. Endocrinol. 146, 45-55.

Bernier, N.J., Craig, P.M., 2005. CRF-related peptides contribute to stress response and regulation of appetite in hypoxic rainbow trout. Am.J. Physiol. Regul. Integr. Comp. Physiol. 289, R982-R990.

Bernier, N.J., Peter, R.E., 2001a. The hypothalamic-pituitary-interrenal axis and the control of food intake in teleost fish. Comp. Biochem. Physiol. 129B, 639-644.

Bernier, N.J., Peter, R.E., 2001b. Appetite-suppressing effects of urotensin I and corticotrophin-releasing hormone in goldfish (Carassius auratus). Neuroendocrinology 73, 248-260.

Bernier, N.J., Bedard, N., Peter, R.E., 2004. Effects of cortisol on food intake, growth, and forebrain neuropeptide $\mathrm{Y}$ and corticotropin-releasing factor gene expression in goldfish. Gen. Comp. Endocrinol. 135, 230-240. 
Bernier, N.J., Lin, X-W., Peter, R.E., 1999. Differential expression of corticotropin-releasing factor (CRF) and urotensin I precursor genes, and evidence of CRF gene expression regulated by cortisol in goldfish brain. Gen. Comp. Endocrinol. 116, 461-477.

Bjornsson, B.Th., Ogasawara, T., Hirano, T., Bolton, J.P., Bern, H.A., 1988. Elevated growth hormone levels in stunted Atlantic salmon, Salmo salar. Aquaculture 73,275281.

Carey, J.B., McCormick, S.D. 1998. Atlantic salmon smolts are more responsive to acute handling and confinement stress than parr. Aquaculture 168, 237-253.

Craig, P.M., Al-Timimi, H., Bernier, N.J., 2005. Differential increase in forebrain and caudal neurosecretory system corticotropin-releasing factor and urotensin I gene expression associated with seawater transfer in rainbow trout. Endocrinology 146, 3851-3860.

Cummings, D.E., Shannon, M.H., 2003. Roles for ghrelin in the regulation of appetite and body weight. Archiv. Surg. 138, 389-396.

Damsgård, B., Arnesen, A.M., 1998. Feeding, growth and social interactions during smolting and seawater acclimation in Atlantic salmon, Salmo salar L. Aquaculture 168, 7-16.

Davis, K.B., Torrance, P., Parker, N.C., Suttle, M.A., 1985. Growth, body composition and hepatic tyrosine aminotransferase activity in cortisol-fed channel catfish, Ictalurus punctatus Rafinesque. J. Fish Biol. 27, 177-184.

Doyon, C., Gilmour, K.M., Trudeau, V.L., Moon, T.W., 2003. Corticotropin-releasing factor and neuropeptide Y mRNA levels are elevated in the preoptic areas of socially subordinate rainbow trout. Gen. Comp. Endocrinol. 133, 260-271.

Doyon, C., Leclair, J., Trudeau, V.L., Moon, T.W., 2006. Corticotropin-releasing factor and neuropeptide Y mRNA levels are modified by glucocorticoids in rainbow trout, Oncorhynchus mykiss. Gen. Comp. Endocrinol. 146, 126-135. 
Doyon, C., Trudeau, V.L., Moon, T.W., 2005. Stress elevates corticotrophin-releasing factor (CRF) and CRF-binding protein mRNA levels in rainbow trout (Oncorhynchus mykiss). J. Endocrinol. 186, 123-130.

Dyer, A.R., Upton, Z., Stone, D., Thomas, P.M., Soole, K.L., Higgs, N., Quinn, K., Carragher, J.F., 2004. Development and validation of a radioimmunoassay for fish insulin-like growth factor I (IGF-I) and the effects of aquaculture stressors on circulating IGF-I levels. Gen. Comp. Endocrinol. 135, 268-275.

Ewing, R.D., Rodgers, J.D., 1998. Changes in physiological indices of smolting during seaward migration of wild coho salmon Oncorhynchus kisutch. Aquaculture 168, 6983.

Flos, R., Reig, L., Torres, P., Tort, L., 1988. Primary and secondary responses to grading and hauling in rainbow trout, Salmo gairdneri. Aquaculture 71, 99-106.

Gregory, T.R., Wood, C.M., 1999. The effects of chronic plasma cortisol elevation on the feeding behaviour, growth, competitive ability and swimming performance of juvenile rainbow trout. Physiol. Biochem. Zool. 72, 286-295.

Handeland, S.O., Björnsson, B.Th., Arnesen, A.M., Stefansson, S.O., 2003. Seawater adaptation and growth of post-smolt Atlantic salmon (Salmo salar) of wild and farmed strains. Aquaculture 220, 367-383.

Hoskonen, P., Pirhonen, J., 2006. Effects of repeated handling, with or without anaesthesia, on feed intake and growth in juvenile rainbow trout, Oncorhynchus mykiss (Walbaum). Aquacult. Res. 37, 409-415.

Huising, M.O., Metz, J.R., van Schooten, C., Taverne-Thiele, A.J., Hermsen, T., Verberg-van Kemenade, B.M.L., Flik, G., 2004. Structural characterization of a cyprinid (Cyprinus carpio L.) CRH, CRH-BP and CRH-R1 and the role of these proteins in the acute stress responses. J. Mol. Endocrinol. 32, 627-648. 
Iwama, G.K., Morgan, J.D., Barton, B.A., 1995. Simple field methods for monitoring stress and general condition of fish. Aquacult. Res. 26, 273-282.

Liebert, A.M., Schreck, C.B. 2006. Effects of acute stress on osmoregulation, feed intake, IGF-1, and cortisol in yearling steelhead trout (Oncorhynchus mykiss) during seawater adaptation. Gen. Comp. Endocrinol. 148, 195-202.

Lin, X-W., Volkoff, H., Narnaware, Y., Bernier, N.J., Peyon, P., Peter, R.E., 2000. Brain regulation of feeding behavior and food intake in fish. Comp. Biochem. Physiol. 126A, 415-434.

MacLeod, M.G., 1977. Effects of salinity on food intake, absorption and conversion in the rainbow trout Salmo gairdneri. Mar. Biol. 43, 93-102.

McCormick, S.D., Shrimpton, J.M., Carey, J.B., O’Dea, M.F., Sloan, K.E., Moriyama, S., Björnsson, B.Th., 1998. Repeated acute stress reduces growth rate of Atlantic salmon parr and alters plasma levels of growth hormone, insulin-like growth factor I and cortisol. Aquaculture 168, 221-235.

McKay, L.R., Gjerde, B., 1985. The effect of salinity on growth of rainbow trout. Aquaculture 49, 325-331.

Nielsen, C., Holdensgaard, G., Petersen, H.C., Björnsson, B.Th., Madsen, S.S., 2001. Genetic differences in physiology, growth hormone levels and migratory behaviour of Atlantic salmon smolts. J. Fish Biol. 59, 28-44.

Otto, B., Tschop, M., Heldwein, W., Pfeiffer, A.F., Diederich, S,. 2004. Endogenous and exogenous glucocorticoids decrease plasma ghrelin in humans. Eur. J. Endocrinol. $151,113-117$.

Pankhurst, N.W., Sharples, D.F., 1992. Effects of capture and confinement on plasma cortisol levels in the snapper Pagrus auratus. Aust. J. Mar. Freshwat. Res. 43, 345-356. 
Pankhurst, N.W., Van Der Kraak, G., 1997. Effects of stress on growth and reproduction. In: Iwama, G.K., Pickering, A.D., Sumpter, J.P., Schreck, C.B. Fish Stress and Health in Aquaculture. Cambridge University Press, Cambridge, pp. 73-93.

Pankhurst, N.W., King, H.R., Ludke, S.L., 1997. Relationship between stress, feeding and plasma ghrelin levels in rainbow trout Oncorhynchus mykiss. Mar. Freshwat. Behav. Physiol. In press.

Peterson, B.C., Small, B.C., 2005. Effects of exogenous cortisol on the GH/IGF/IGFBP network in channel catfish. Dom. Anim. Endocrinol. 28, 391-404.

Pfaff, D.W., Phillips, M.I., Rubin, R.T., 2004. Principles of Hormone/Behaviour Relations. Elsevier, Amsterdam. 335p.

Pickering, A.D., 1993. Growth and stress in fish production. Aquaculture 111, 51-63.

Proulx, K., Vahl, T.P., Drazen, D.L., Woods, S.C., Seeley, R.J., 2005. The effect of adrenalectomy on ghrelin secretion and orexigenic action. J. Neuroendocrinol. 17, 445-451.

Schreck, C.B., Olla, B.L., Davis, M.W., 1997. Behavioral responses to stress. In: Iwama, G.K., Pickering, A.D., Sumpter, J.P., Schreck, C.B. Fish Stress and Health in Aquaculture. Cambridge University Press, Cambridge, pp. 145-170.

Shepherd, B.B., Johnson, J.K., Silverstein, J.T., Parhar, I.S., Vijayan, M.M., McGuire, A., Weber, G.M., 2007. Endocrine and orexigenic actions of growth hormone secretagogues in rainbow trout (Oncorhynchus mykiss). Comp. Biochem. Physiol. 146A, 390-399.

Shousha, S., Nakahara, K., Kojima, M., Miyazato, M., Hosoda, H., Kangawa, K., Murakami, N., 2005. Different effects of peripheral and central ghrelin on regulation of food intake in the Japanese quail. Gen. Comp. Endocrinol. 141, 178-183. 
Sumpter, J.P., 1997. The endocrinology of stress. In: Iwama, G.K., Pickering, A.D., Sumpter, J.P., Schreck, C.B. Fish Stress and Health in Aquaculture. Cambridge University Press, Cambridge, pp. 95-118.

Tasker, J.G., Di, S., Malcher-Lopes, R., 2006. Minireview: Rapid glucocorticoid signaling via membrane-associated receptors. Endocrinology 147, 5549-5556.

Thomas, P., 2003. Rapid, nongenomic steroid actions initiated at the cell surface: lessons from studies with fish. Fish Physiol. Biochem. 28, 3-12.

Thomas, P.M., Pankhurst, N.W., Bremner, H.A., 1999. The effect of stress and exercise on post-mortem biochemistry of Atlantic salmon (Salmo salar) and rainbow trout (Oncorhynchus mykiss). J. Fish Biol. 54, 1177-1196.

Unniappan, S., Peter, R.E., 2005. Structure, distribution and physiological functions of ghrelin in fish. Comp. Biochem. Physiol. 140A, 396-408.

Unniappan, S., Canosa, L.F., Peter, R.E., 2004. Orexigenic actions of ghrelin in goldfish: Feeding-induced changes in brain and gut mRNA expression and serum levels, and responses to central and peripheral injections. Neuroendocrinology 79, 100-108.

Usher, M.L., Talbot, C., Eddy, F.B., 1991. Effects of transfer to seawater on growth and feeding in Atlantic salmon smolts (Salmo salar L.). Aquaculture 94, 309-326.

Volkoff, H., Canosa, L.F., Unniappan, S., Cerdá-Reverter, J.M., Bernier, N.J., Kelly, S.P., Peter, R.E., 2005. Neuropeptides and the control of food intake in fish. Gen. Comp. Endocrinol. 142, 3-19. 
Table 1. Food ingestion (\% of food eaten $)^{1}$ by groups $(n=7)$ of parr, smolts and post-smolts in 2004 presented with a 2 minute feeding opportunity either without (No-stress), or at various times after a $1 \mathrm{~h}$ confinement stress.

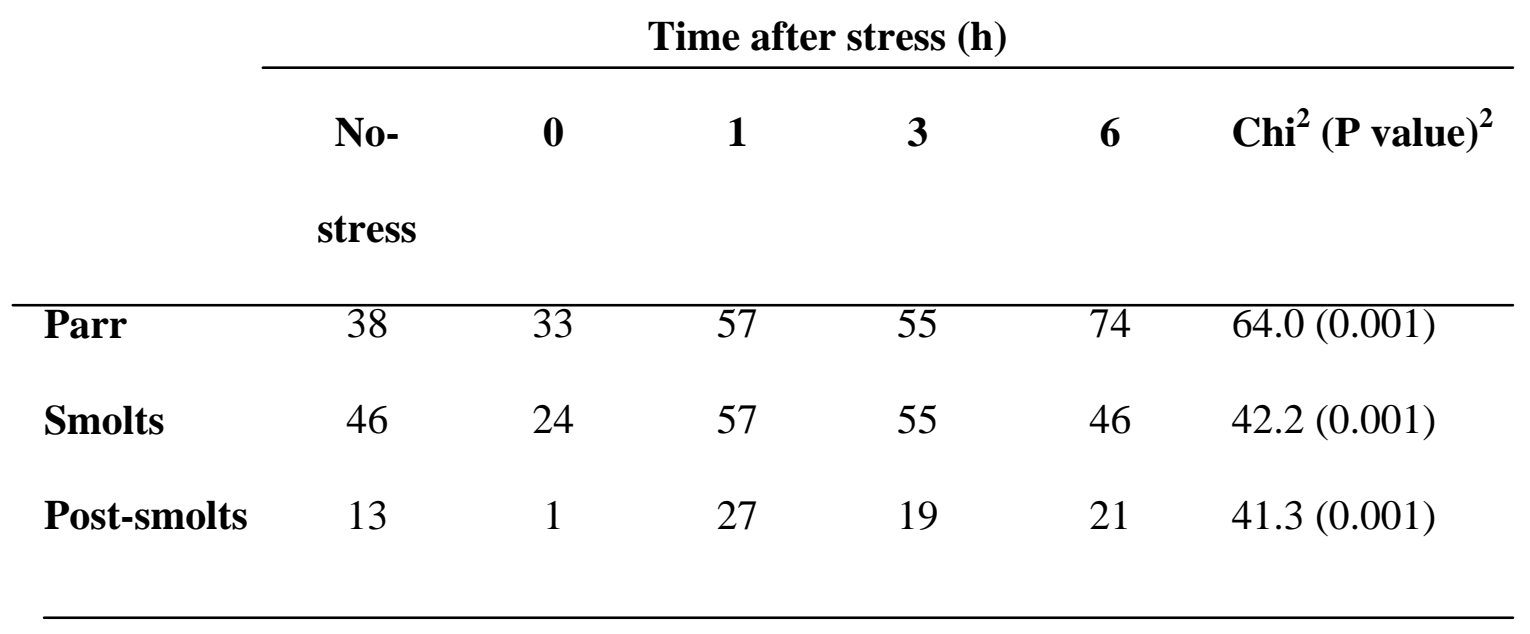

${ }^{1}$ One hundred and fifty pellets presented to each group; pellet size $=2,3$ and $4 \mathrm{~mm}$ for parr, smolts and post-smolts to give meals sizes $3.5,5.0$ and $4.0 \%$ of body weight respectively.

${ }^{2}$ Comparison of eaten vs uneaten pellets across time. 
Table 2. Food ingestion by pre-smolts, and smolts in 2005 presented with a 3 minute feeing opportunity either without (unstressed), or following a 1h confinement stress (stressed).

\begin{tabular}{llll} 
Treatment Group & No. pellets eaten & Total pellet & Proportion of fish \\
& per fish $^{1}$ & ingestion $^{2}$ & feeding (\%) \\
\hline
\end{tabular}

Pre-smolts

Unstressed

$0.7 \pm 0.2^{\mathrm{a}} \quad 3 *^{3}$

32

Stressed

$0.4 \pm 0.1^{\mathrm{a}}$

22

24

Smolts

Unstressed

$7.1 \pm 0.5^{\mathrm{c}}$

353*

100 *

Stressed

$2.5 \pm 0.4^{\mathrm{b}}$

128

62

${ }^{1}$ Values are mean \pm SE $(n=50)$. Different superscripts show significantly different values $(\mathrm{P}<0.05)$

${ }^{2}$ Total food offered $=668,661,648$ and 667 pellets for the four groups respectively.

3* = significant $\mathrm{Chi}^{2}$ value between unstressed and stressed. 


\section{Figure legends}

Fig. 1 Plasma levels of cortisol (ng.ml ${ }^{-1}$ ) and glucose (mM) in 2004 cohort undisturbed parr, smolts and post-smolts in outdoor tanks (Outside), and without (No-stress), or at various times after a $1 \mathrm{~h}$ confinement period, following transfer to indoor tanks. Values are mean $+\mathrm{SE}(\mathrm{n}=7)$. Values that are significantly different $(\mathrm{P}<0.05)$ have different superscripts.

Fig. 2 Plasma levels of ghrelin (pg.ml ${ }^{-1}$ ) in 2004 cohort parr, smolts and post-smolts. Other details as for Fig. 1.

Fig. 3 Plasma levels of cortisol (ng.ml ${ }^{-1}$ ), glucose (mM) and ghrelin (pg.ml ${ }^{-1}$ ) in 2005 cohort pre-smolts, and smolts that were either unstressed (U), or sampled after $1 \mathrm{~h}$ of confinement stress $(S)$. Values are mean + SE $(n=50)$. Values that are significantly different $(\mathrm{P}<0.05)$ have different superscripts. 

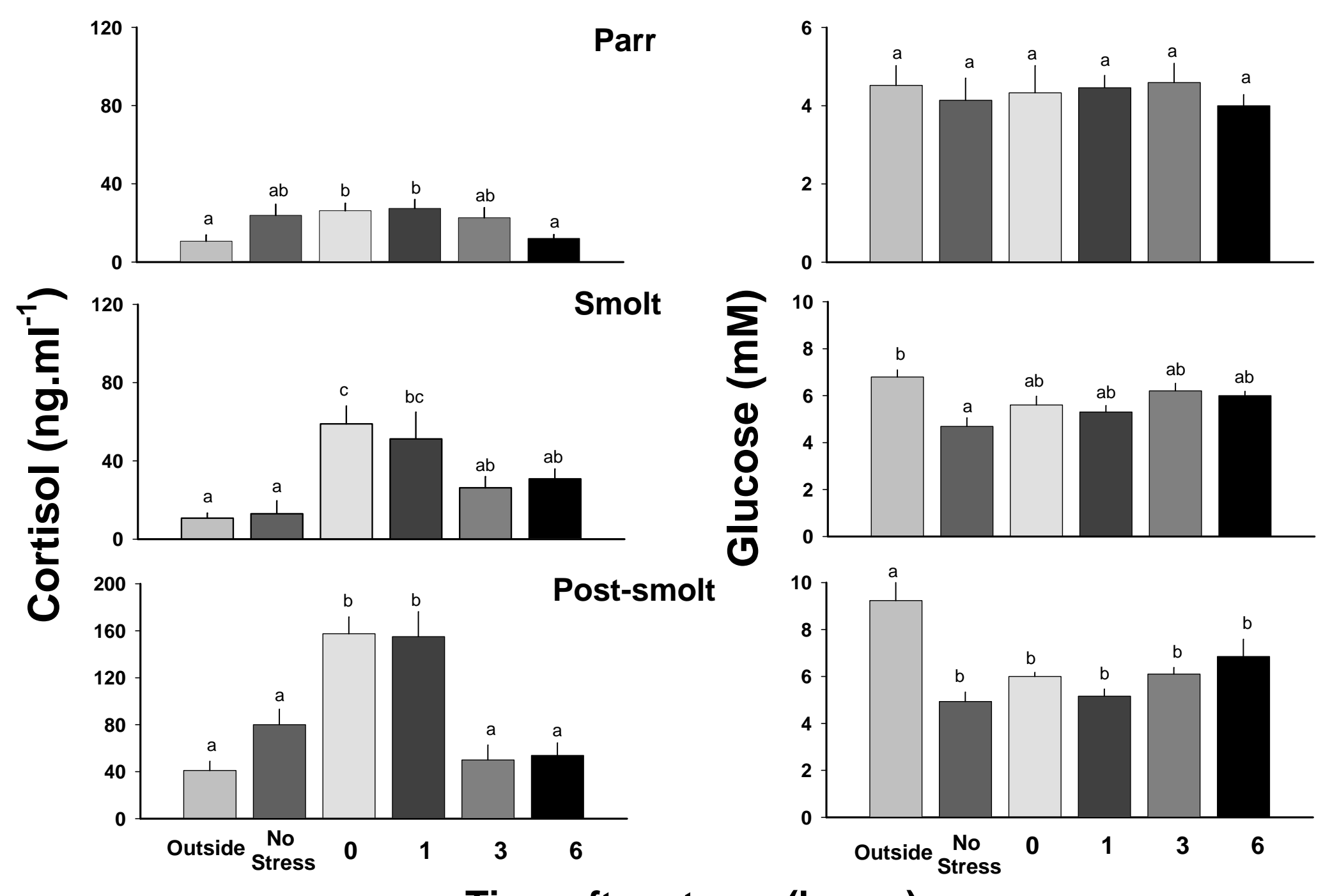

Time after stress (hours) 


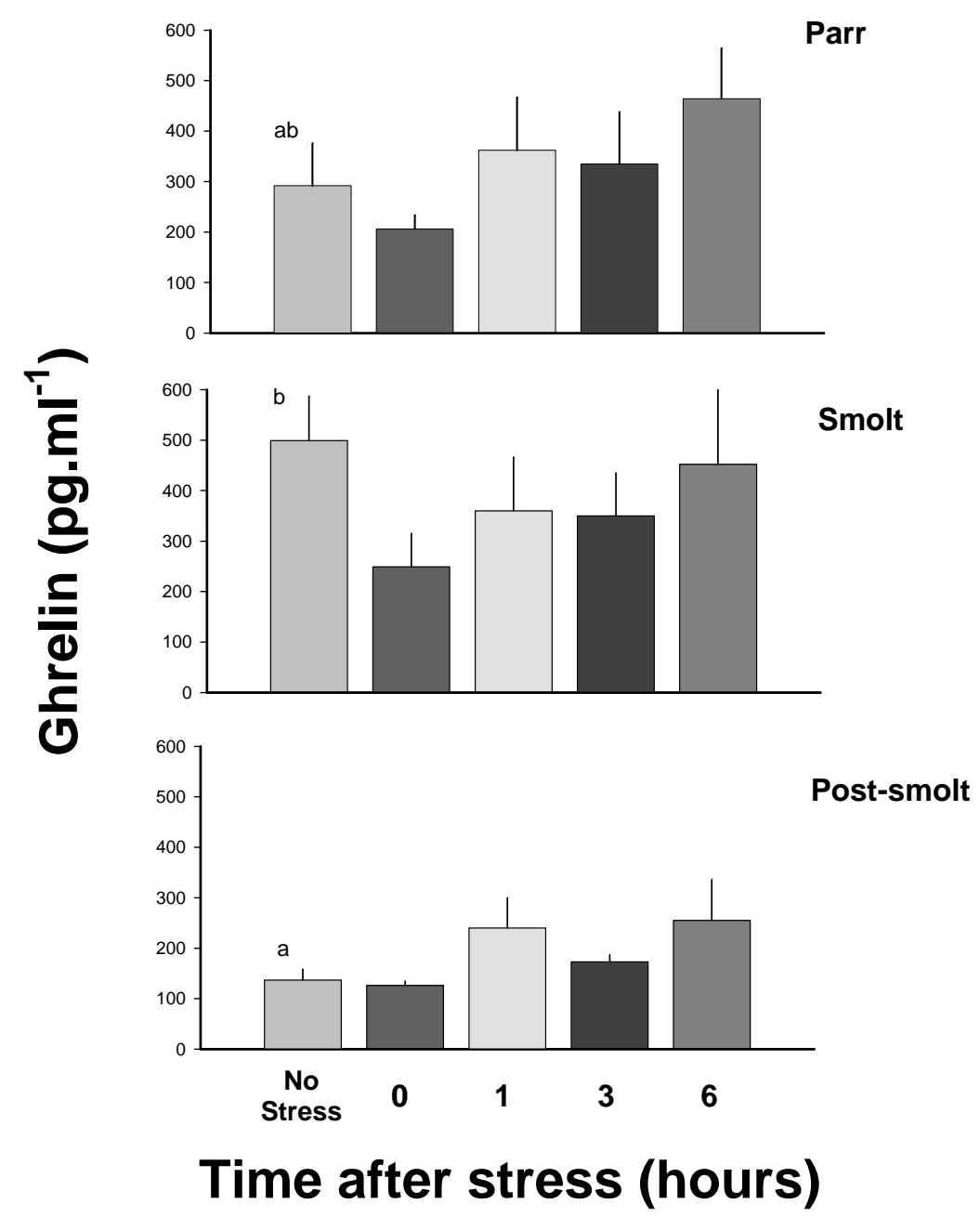



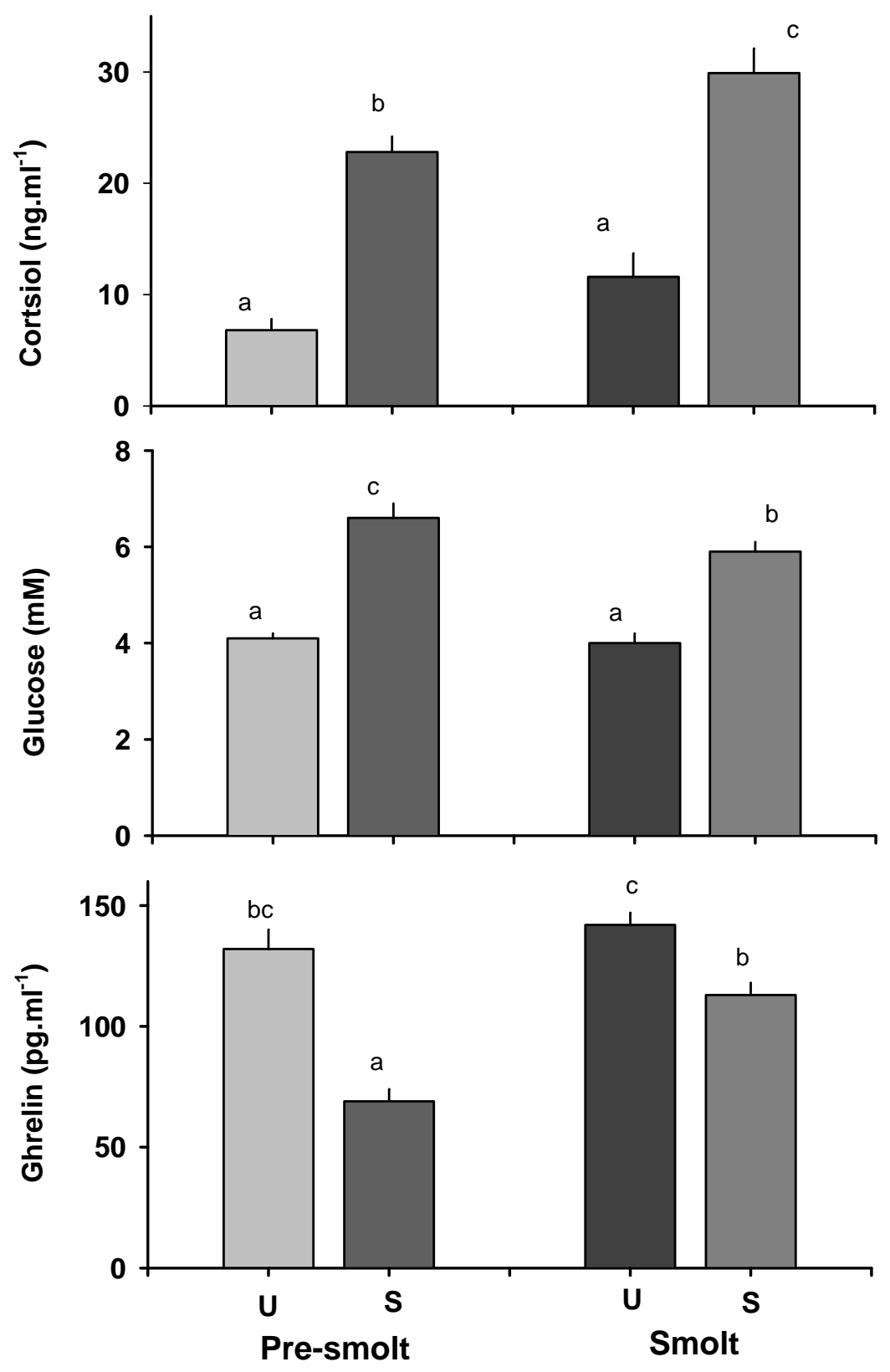

Treatment

Figure 3

5

6 